\title{
SECONDARY MANIA IN AN ELDERLY PATIENT DURING SARS-COV-2 INFECTION WITH COMPLETE REMISSION; A 1-YEAR FOLLOW-UP
}

\author{
Sara Jiménez-Fernández ${ }^{1,2}$, Mirta Olga Solis ${ }^{1}$, Isabel Martínez-Reyes ${ }^{1}$, Ana Alvarado-Dafonte ${ }^{1}$, \\ Luis Soldado-Rodríguez ${ }^{1}$ \& Maria Isabel Rodríguez-Natal \\ ${ }^{1}$ Department of Psychiatry, University Hospital of Jaén, Jaén, Spain \\ ${ }^{2}$ Department of Psychiatry, University of Granada, Granada, Spain
}

received: 6.5.2021;

revised: 28.6.2021; accepted: 6.7 .2021

\section{INTRODUCTION}

The new Severe Acute Respiratory Syndrome Coronavirus 2 (SARS-CoV-2) appeared in Wuhan (capital city of Hubei Province, China) in December 2019, resulting in an international public health emergency by the end of January 2020 according to The World Health Organization (WHO). The clinical presentation of the new disease consisted of severe respiratory syndrome secondary to acute lung damage. It was also found that other organs were invaded by the new coronavirus.

The most typical symptoms in previous coronavirusses were confusion, insomnia, depression and anxiety. Mania and psychosis appeared in low percentages, but subthreshold symptoms were found with more frequency (Rogers et al. 2020). Described cases of mania and psychosis have shown a complete recovery after the infection without the development of chronic mental illness (Noone et al. 2020, Tuna et al. 2020). However, psychiatric consequences of the infection are multifactorial, and existing literature could have serious limitations in observational studies, due to the size of the sample or the short follow-up time (Rogers et al. 2020).

Here we present the case of a patient with a possible atypical presentation of SARS-CoV-2 infection with affective mania symptoms. In the present description of the case, data that allowed the identification of the patient was omitted to guarantee privacy.

\section{CASE REPORT}

A retired male patient of 71 was admitted to the Emergency Unit of an University Hospital of Andalusia, Spain in March 2020. Over the previous days, the family had observed an abrupt change in the patient's behavior; he was very excited and talkative, with pressured speech, as well as being euphoric, energetic with excessive motor activity and suffering from global insomnia. He exhibited megalomaniacal ideas and delusions of being the World champion in a sport that he practices as an amateur or of being persecuted. He made sexual and inappropriate comments and he was spending significant amounts of money.
The patient's cognition was also severely affected. He was confused and disorientated, with important memory failures (were not able to remember where his car was). As a consequence, his family doctor recommended an urgent examination to rule out an organic condition.

In the previous month before the patient had been treated with corticosteroids for a recurrent varicella-zoster chest-skin lesion. On two previous occasions during treatment with corticosteroids, the patient had presented mild delirium episodes characterized by short-term fluctuating confusion. On this occasion, during the treatment with steroids the patient presented fluctuating disorientation with a complete recovery but a week after that, the patient suddenly developed severe manic symptoms and confusion that required hospitalization in a psychiatric unit after ruling out any organic conditions.

The brain computed tomography (BCT) showed cortico-subcortical retraction pattern and blood tests found slight non-specific abnormalities (Table 1). The physical examination revealed a body temperature of $38^{\circ} \mathrm{C}$, with a mild cough and dizziness. Due to the new coronavirus pandemic situation, a PCR for SARS-CoV2 RNA was performed with a positive result (other possible infectious causes were ruled out).

The patient underwent treatment with atypical antipsychotics and benzodiazepines (quetiapine $75 \mathrm{mg}$ per day and clonazepam $1 \mathrm{mg}$ per day) and showed significant improvement after a week. The patient was released from hospital with psychiatric medication that he continued taking for a period of 3 months. A year after that he did not exhibit any affective symptoms, but mild cognitive impairment was presented.

\section{DISCUSSION}

We present a rare manifestation of acute manic symptoms in an elderly patient with no medical history of major affective disorders in the context of SARS$\mathrm{CoV}-2$ infection. The diagnosis of mania in old age is complicated to perform because the manic symptoms could be masking other organic conditions such as cognitive impairment and delirium. 
Table 1. Blood results before, during hospitalization and after 1 year follow-up

\begin{tabular}{|c|c|c|c|c|c|}
\hline Biochemical parameters & Unit & $\begin{array}{l}\text { 2-days before of } \\
\text { the hospitalization }\end{array}$ & $\begin{array}{l}\text { First day of the } \\
\text { hospitalization }\end{array}$ & $\begin{array}{c}\text { 1-year } \\
\text { follow-up }\end{array}$ & $\begin{array}{c}\text { Reference } \\
\text { value }\end{array}$ \\
\hline Red blood cells & x $10^{6} / \mu \mathrm{L}$ & 5.24 & 5.2 & 5.34 & $4.0-5.5$ \\
\hline Haemoglobin & $\mathrm{g} / \mathrm{dL}$ & 14.7 & 14.7 & 15.3 & $13.0-18.0$ \\
\hline Hematocrit & $\%$ & 46.4 & 45.6 & 47.6 & $40.0-54.0$ \\
\hline Mean cell volumen & $\mathrm{fL}$ & 88.5 & 87.7 & 89.1 & $82.0-95.0$ \\
\hline Plaquelets & x $10^{3} / \mu \mathrm{L}$ & 233 & 180 & 200 & $130-450$ \\
\hline White cell count & $\mathrm{x} 10^{3} / \mu \mathrm{L}$ & 12.59 & 8.37 & 5.44 & $3.7-9.7$ \\
\hline Neutrophils & $\times 10^{3} / \mu \mathrm{L}$ & 11.48 & 6.24 & 2.3 & $2.0-7.5$ \\
\hline Lynphocytes & $\times 10^{3} / \mu \mathrm{L}$ & 0.72 & 1.51 & 2.32 & $1.0-4.0$ \\
\hline Monocytes & $\mathrm{x} 10^{3} / \mu \mathrm{L}$ & 0.37 & 0.55 & 0.53 & $0.00-1.00$ \\
\hline Eosinophils & x $10^{3} / \mu \mathrm{L}$ & 0.01 & 0.07 & 0.20 & $0.00-0.03$ \\
\hline Basophils & x $10^{3} / \mu \mathrm{L}$ & 0.01 & 0.01 & 0.06 & $0.00-0.10$ \\
\hline Protrombin time & $\mathrm{s}$ & 10.1 & 10.7 & - & $11.0-14.0$ \\
\hline Activated partial prothomplastin time & $\mathrm{s}$ & 24.1 & 26.4 & - & $25.0-37.0$ \\
\hline Fibrinogen & $\mathrm{mg} / \mathrm{dL}$ & 434 & 589 & - & $150-400$ \\
\hline Glucose & $\mathrm{mg} / \mathrm{dL}$ & 133 & 83 & 102 & $74-106$ \\
\hline Urea & $\mathrm{mg} / \mathrm{dL}$ & 53 & 44 & - & $10-50$ \\
\hline Creatinine & $\mathrm{mg} / \mathrm{dL}$ & 0.83 & 0.98 & 1.20 & $0.70-1.20$ \\
\hline Sodium & $\mathrm{mEq} / \mathrm{L}$ & 138 & 135 & 142 & $136-145$ \\
\hline Potassium & $\mathrm{mEq} / \mathrm{L}$ & 4.7 & 4.2 & 4.1 & $3.5-5.1$ \\
\hline $\mathrm{C}$ reactive protein & $\mathrm{mEq} / \mathrm{L}$ & - & 30.4 & - & $0.0-5.0$ \\
\hline IgG antibodies (S1/S2) & - & - & - & positive & - \\
\hline
\end{tabular}

Late-life mania is heterogenous as it includes the late onset of bipolar mania, secondary mania and latelife neuropsychiatric conditions as dementia or hyperactive-type delirium (Singh et al. 2015). Mania together with confusion, fluctuations in alertness, and sleep-wake-cycle reversal with deterioration in symptoms at night is usually associated with hyperactive delirium and is accompanied by comorbid cognitive dysfunction or dementia. However, when mania is followed by acute deterioration of cognitive abilities with rapid fluctuation of mood and energy levels, it is indicative of a manic episode (Singh et al. 2015).

The pathophysiology of early- and late-onset mania would be different; while in early-onset mania it is common to have close relatives with an affective illness it is less frequent in older patients, and in those patients, mania seems to be associated with aging, infectious conditions and treatments (Tohen et al. 1994). Differences in the evolution of the disease have also been described; older-age bipolar mania is normally characterized by high medical comorbidity, cognitive deficiency, and impaired functioning and a burden on family caregivers (Chen et al. 2017).

In 1978 "secondary mania" was described in elderly patients with first episode mania and found that this diagnosis is associated with high rates of mortality. This was later confirmed among elderly men suffering from mania, especially when neurological comorbidities are presented (Tohen et al. 1994). Secondary or organic mania is characterized by the presence of mania in the absence of attention fluctuations, which is the main difference to delirium. It includes persistent elevated, expansive or irritable mood, with inflated self-esteem, diminished need for sleep, talkativeness, racing thoughts (flights of ideas), distractibility, psychomotor agitation and/or excessive involvement in pleasurable activities (Krauthammer \& Klerman 1978).

Delirium and secondary mania are both distinct and overlapping symptoms, and it is necessary to be cautious because incorrectly attributing them to agents or drugs could be dangerous, taking into account that their treatment would require completely different procedures. While guidelines recommend the avoidance of benzodiazepines in the treatment of deliriumexcept in the case of alcohol withdrawal or seizures (American Psychiatric Association 1999), they can be useful when dealing with secondary mania together with organic treatment, if needed.

In this report, the two possible conditioning factors are being infected with the new coronavirus and treatment with corticosteroids. However, the treatment with corticosteroids produces psychiatric disturbances at high doses and normally improve upon dose reduction (Sirosis 2003).

On the other hand, SARS-Cov-2 virus is implicated in the development of neuropsychiatric symptoms and some authors have established a connection with psychosis and mania (Noone et al. 2020, Tuna et al. 2020) through direct viral transmission (Yesilkaya \& Balcioglu 2020) and the neuroimmune response supported by the presence of biochemical alterations (Rogers et al. 2020). Patients with CNS symptoms have shown low lymphocyte counts compared to patients without CNS symptoms, and this alteration seems to be especially relevant in the subgroup of severe patients (Rogers et al. 2020). 


\section{CONCLUSION}

The patient presented the psychopathological characteristics of late-onset mania without the fluctuating pattern of cognitive symptoms but, some specific factors could be more suggestive of secondary mania: the lack of history of affective disorders, the concurrence at the time of treatment and some age-related brain lesions, the lack of affective during the following year, mild cognitive impairment and the concurrence with the new coronavirus infection.

Doctors should think about the importance of an exhaustive evaluation of mental health status in order to contribute to a better understanding of the SARS-CoV-2 infection.

\section{Acknowledgements: None.}

\section{Conflict of interest: None to declare.}

\section{Contribution of individual authors:}

Sara Jiménez-Fernández \& Mirta Olga Solis designed, wrote and reviewed the the manuscript.

Isabel Martínez-Reyes, Ana Alvarado-Dafonte, Luis Soldado-Rodríguez \& Maria Isabel Rodríguez-Natal reviewed the manuscript.

All the author approved the last version of the manuscript.

\section{Correspondence:}

Sara Jiménez-Fernández, MD

Department of Psychiatry, University Hospital of Jaén

Carretera Bailén-Motril s/n, 23001, Jaén, Andalusia, Spain

E-mail: sarajimenezfer@hotmail.com

\section{References}

1. American Psychiatric Association: Practice guideline for the treatment of patients with delirium. Am J Psychiatry 1999; 156:1-20

2. Chen P, Dols A, Rej $S$ \& Sajatovic M: Update on the epidemiology, diagnosis, and treatment of mania in olderage bipolar disorder. Geriatric disorders 2017; 19:46

3. Krauthammer $C \&$ Klerman GL: Secondary mania. Arch Gen Pyschiatry 1978; 35:1333-1339

4. Noone R, Cabassa JA, Gardner L, Schwartz B, Alpert JE \& Gabbay V: New onset psychosis and mania following COVID19 infection. J Psychiatr Res 2020; 130:177-179

5. Rogers JP, Chesney E, Oliver D, Pollak TA, McGuire P, Fusar-Poli $P$ et al.: Psychiatric and neuropsychiatric presentations associated with severe coronavirus infections: a systematic review and meta-analysis with comparison to the COVID-19 pandemic. Lancet 2020; 7:611627

6. Singh P, Pandey NM \& Tiwari SC: Late-life mania: a brief review. J of geriatric mental health 2015; 2:68-73

7. Sirosis F: Steroid psychosis: a review. Gen Hosp Psychiatry 25:27-33

8. Tohen M, Shulman KI \& Satlin A: First-episode mania in late life. Am J Psychiatry 1994; 151:130-132

9. Tuna O, Salman $S \&$ Darcin AE: COVID-19 pandemic in delusion: two cases. Psychiatr Danub 2020; 32:592-593

10. Yesilkaya UH \& Balcioglu YH: Neuroimmune correlates of the nervous system involvement of COVID-19: A commentary. J Clin Neurosci 2020; 78:449-450 